\title{
Periarterial abscess: another cause of cyanosis after pulmonary artery banding
}

\author{
SERGIO A BATTISTESSA, PIOTR L BURCZYNSKI, ROXANE McKAY \\ From the Royal Liverpool Children's Hospital
}

SUMMARY Twenty seven months after pulmonary artery banding a boy aged two and a half developed rapidly progressive cyanosis. A periarterial abscess was found at the site of the band. Repair of the pulmonary artery and closure of the ventricular septal defect were complicated by profoundly low cardiac output and prolonged dependence on a ventilator. This near fatal complication would have been avoided by primary closure of the ventricular septal defect.

Constriction of the pulmonary artery to reduce pulmonary blood flow in the presence of an isolated ventricular septal defect is usually well tolerated and rapidly controls congestive heart failure. Although ventricular hypertension leads to progressive hypertrophy of the right heart, patients generally grow well and are usually symptom free for several years after a satisfactory banding operation. ${ }^{12}$ The gradual appearance of cyanosis indicates the reversal of the intracardiac shunt, as the resistance in the enlarging systemic circulation progressively falls below that offered by the fixed diameter of the main pulmonary artery. A sudden onset or rapid progression of cyanosis, however, is more ominous, and in the patient presented here resulted from a serious and previously unreported complication of pulmonary artery banding.

\section{Case report}

A boy with Down's syndrome, who weighed $11 \mathrm{~kg}$, was referred with increasing cyanosis and breathlessness at the age of two and a half. He had had severe congestive heart failure with failure to thrive in infancy, and cardiac catheterisation showed systemic pressure in the pulmonary artery with a large left to right shunt through a perimembranous ventricular septal defect. Pulmonary artery banding had been performed, without complication, at the referring institution when he was four months old, and he subsequently made satisfactory progress. Two months before admission, his mother noted slight

Requests for reprints to Roxane McKay, FRCS, Royal Liverpool Children's Hospital, Myrtle Street, Liverpool L7 7DG. central cyanosis, and five weeks later his condition rapidly deteriorated.

On examination, the boy was deeply cyanosed, lethargic, and tachypnoeic at rest. A grade 3/6 systolic murmur radiated from the left sternal border to the pulmonary area, but a thrill was not palpable. His chest was clear, but there was severe finger clubbing. The remainder of his examination showed findings that are typical of Down's syndrome but no other significant abnormality.

A chest $x$ ray showed severely oligaemic lung fields and moderate cardiac enlargement, while the electrocardiogram showed right ventricular hypertrophy. Real time echocardiography showed a large ventricular septal defect and good ventricular function. On Doppler examination, a velocity of $4 \mathrm{~m} / \mathrm{s}$ across the band suggested a gradient of $64 \mathrm{~mm} \mathrm{Hg}$. At cardiac catheterisation, pressure in the right ventricle was suprasystemic, and oxygen saturation in the aorta was $28 \%$ (table). Angiography confirmed the presence of a perimembranous ventricular septal defect, a tight pulmonary artery band, and a main

Table Data from cardiac catheterisation

\begin{tabular}{lcl}
\hline & $\begin{array}{l}\text { Pressures } \\
(\text { mm Hg) }\end{array}$ & $\begin{array}{l}\text { Oxygen saturation } \\
(\%)\end{array}$ \\
\hline RA & 7 & 26 \\
RV & $115 / 10$ & 26 \\
PA & $80 / 0$ & -10 \\
LV & $95 / 5$ & 28 \\
Aorta & $90 / 45$ &
\end{tabular}

«Proximal to the band.

$\mathrm{RA}$, right atrium; $\mathrm{RV}$, right ventricle; $\mathrm{LV}$, left ventricle; $\mathrm{PA}$, pulmonary artery.

Pressures are given as systolic/diastolic for the RV, PA, LV, and aorta and mean for the RA. 
Fig Lateral view of the right ventriculogram showing severe constriction at the banding site and the profile of the abscess mass (arrows).

pulmonary artery with a long, irregular profile (figure).

In view of the probable thrombotic obstruction of the pulmonary artery, urgent debanding and closure of the ventricular septal defect were carried out on cardiopulmonary bypass. The pericardial space was obliterated by friable vascular adhesions, which suggested an active inflammatory process, and on palpation the position of the band was ill-defined as the result of dense fibrous tissue overlying the pulmonary artery. An incision into this mass entered a large abscess cavity containing thick, yellow pus under tension. The arterial endothelium was intact but a considerable portion of the main pulmonary artery had been destroyed by infection, and a silk ligature that had been used to band the pulmonary artery restricted the diameter of the lumen to about $3 \mathrm{~mm}$ at the bottom of the abscess cavity.

After evacuation of the abscess cavity, the pulmonary artery was reconstructed by end to end anastomosis posteriorly and a patch of autogenous pericardium anteriorly. The large, perimembranous ventricular defect was closed with a Dacron patch. Despite an initial pressure ratio of 0.53 between right and left ventricles, the patient had severe low cardiac output, which failed to respond to dopamine, isoprenaline, and adrenaline, in the immediate postoperative period. Chest $x$ rays showed pulmonary oedema and subsequently collapse of the right upper lobe. Haemodynamic function gradually improved on the second postoperative day, but five days of mechanical ventilation and inotropic support were required before his condition stabilised. The remainder of his three week convalescence in hospital was uneventful. Pus from the abscess cavity was sterile.

\section{Discussion}

Before surgical correction of cardiac defects was feasible in infancy, pulmonary artery banding was used to palliate various malformations associated with excessive pulmonary blood flow. ${ }^{2}$ Progressive, dense fibrosis of the arterial wall was seen as early as 14 weeks after pulmonary artery banding, ${ }^{34}$ and 
similar thickening was found in the pulmonary valve itself. ${ }^{145}$ Distal migration of the band ${ }^{13}$ may cause preferential constriction of the right pulmonary artery and complicate debanding, ${ }^{4}$ while erosion into the lumen of the pulmonary artery ${ }^{67}$ occasionally produces cataclysmic haemorrhage. Calcification of the proximal pulmonary artery and the band site itself ${ }^{8}$ and septic ulceration resulting in rupture of the vessel ${ }^{7}$ are rare events. About $10 \%$ of patients in whom the pulmonary artery is banded will develop obstruction of the left ventricular outflow tract,' and obstructive right ventricular hypertrophy has been reported. ${ }^{14}$

The only other patient in whom a sudden and rapid deterioration with progressive cyanosis and clubbing was reported was found to have thrombosis of the pulmonary artery and died in severe low cardiac output six hours after operation. ${ }^{10}$ In our patient, it seems clear that the expanding abscess compressed the pulmonary artery and produced a critical reduction in pulmonary blood flow. Though it is difficult to account for the lack of fever or other signs of infection, this may have been the result of the impaired immune system associated with Down's syndrome. ${ }^{11}$ Certainly, the patient's rapid clinical deterioration over a period of a few weeks contrasts sharply with gradual development of cyanosis that occurs as the band is "out-grown". Such deterioration should prompt urgent reinvestigation because it suggests occlusion of the main pulmonary artery. Given the present excellent results of primary closure of the ventricular septal defect in infancy ${ }^{12}$ and this near fatal complication of palliative surgery, there seems to be little justification in contining to perform pulmonary artery banding in patients with isolated ventricular septal defect.

We thank Dr Raman Patel and Dr Robert Arnold for permission to report this case. PLB was supported by the National Heart Research Fund.

\section{References}

1 Patel RG, Ihenacho HNC, Abrams LD, et al. Pulmonary artery banding and subsequent repair in ventricular septal defect. Br Heart J 1973;35:651-6.

2 Stewart S, Harris P, Manning J. Pulmonary artery banding. An analysis of current risks, results and indications. J Thorac Cardiovasc Surg 1980;80:432-6.

3 Dobell ARC, Murphy DA, Poirier NL, Gibbons JE. The pulmonary artery after debanding. $J$ Thorac Cardiovasc J 1973;65:32-6.

4 Mahle S, Nicoloff DM, Knight L, Moller JH. Pulmonary artery banding: long term results in 63 patients. Ann Thorac Surg 1979;27:216-24.

5 Formanek G, Hunt C, Castaneda A, Moller J, Amplatz K. Thickening of pulmonary valve leaflets following pulmonary artery banding. Radiology 1971;98:75-8.

6 Verel D, Taylor DG, Emery IL. Failure of pulmonary artery banding due to migration of the band. Thorax 1970;25:126-8.

7 Rohmer I, Brom AG, Nauta I. Bands inside the pulmonary artery. A complication of the DammanMuller procedure. Ann Thorac Surg 1967;3:449-54.

8 Parameswaran R, Maranhao V, Ablaza SGG, Goldberg $H$. Calcification of the pulmonary artery: a complication of the banding procedure. Chest 1970;57:577-9.

9 Freed MD, Rosenthal A, Plauth WH Jr, Nadas AS. Development of subaortic stenosis after pulmonary artery banding. Circulation 1973;42-43(suppl III): 7-10.

10 Osborn IR, Hall RI, Winn DF Jr, Capper'RS, Blake HA. An unusual late complication of pulmonary artery banding. Circulation 1966;34:61-4.

11 Miller ME, Mellman WI, Cohen MM, Kohn G, Dietz IR. Depressed immunoglobulin $G$ in newborn infants with Down's syndrome. J Pediatr 1969;75:996-1000.

12 Kirklin JW, Barratt-Boyes BG. Cardiac surgery. New York: John Wiley and Sons, 1986:599-653. 